\title{
POLY ETHER-ETHER KETONE VENEERED WITH COMPOSITE VERSUS PORCELAIN FUSED TO METAL FULL ARCH FIXED SCREW RETAINED PROSTHESIS FOR ATROPHIED MANDIBULAR RIDGES. ONE YEAR RANDOMIZED CLINICAL AND RADIOGRAPHIC TRIAL STUDY
}

\author{
Ramy Moustafa Moustafa Ali * and Mohamad Hossam El-Din Helmy**
}

\begin{abstract}
Purpose: to investigate outcomes of Poly ether-ether ketone veneered with composite and porcelain fused to metal Full arch fixed screw retained prosthesis for patients with atrophied mandibular ridges.

Material and methods: Eight (4 men and 4 women) edentulous patients complaining from mandibular ridge atrophy were randomly assigned into 2 groups; Group I included 4 patients who received 8 implants and porcelain fused to metal full arch fixed restoration, Group II included 4 patients who received 8 implants and Poly ether-ether (PEEK) fixed restoration veneered with composite resin teeth. All implants were inserted using computer guided flapless surgical approach and loaded by definitive restorations after 3 months of osseointegration. Clinical (plaque and gingival index, probing depth, implant stability) and radiographical (bone resorption using cone beam CT) evaluations were performed at time of prosthesis insertion, after 6 month and one year thereafter.

Results: The survival was $90.7 \%$ and $100 \%$ in group I and group II respectively. Plaque and gingival indices increased with time in metal group only and PEEK group showed significant lower plaque and gingival indices than metal group after 6 and 12 months. Probing depth and bone resorption showed an increase values with passage of time in both groups and PEEK group showed significant lower probing depths and bone losses than metal group. Implant stability did not differ between groups or observation times was noted

Conclusion: Within limitations short term randomized trial, it could be concluded that Poly ether-ether ketone veneered with composite full arch fixed screw retained prosthesis is advantageous than porcelain/metal restoration for patients with atrophied mandibular ridges as it showed favourable per-implant tissue health after one 12 months.
\end{abstract}

KEYWORDS: Poly ether-ether ketone Restoration, Completely edentulous patients, Implant supported Prosthesis

* Assistant Professor, Department of Prosthodontics, College of Dentistry, King Faisal University, Al Ahsa, kingdom of Saudia Arabia - Lecturer, Department of Removable prosthodontics, Faculty of Dentistry, Fayoum University, Fayoum, Egypt.

** Lecturer, Department of Removable Prosthodontics, Faculty of Dentistry, Assiut University, Assiut, Egypt 


\section{INTRODUCTION}

Edentulous patients with a severely resorbed mandible have experience problems with their conventional dentures due to an impaired load bearing capacity $^{1,2}$, decrease masticatory performance, loss of function, diminished motor control of the tongue, reduced bite force, and decreased oral sensory function. ${ }^{3-6}$. For the rehabilitation of the atrophied edentulous mandible, the best approach aimed to lessen the distal cantilever without compromising the functional support, elimination of demanding bone grafting procedures, lessening of total treatment time and cost. ${ }^{7}$. Completely edentulous mandible with posterior mandibular atrophy can be managed by insertion of multiple implants in the interforaminal area of the mandible and the use of several fixed implant prosthetic options, such as fixed implant supported hybrid prosthesis ${ }^{8}$ and inclined posterior implants (the all-on-four concept) ${ }^{9,10}$. However, these treatment modalities involve presence of cantilever extensions which increase the incidence of prosthetic and biological complications ${ }^{11}$, unequally distribute masticatory forces, and make a higher strain concentrations at the implant adjacent to cantilevers ${ }^{12,13}$. The use of short implants $(\leq 8 \mathrm{~mm})$ with reduced posterior mandibular ridge height could be an alternative treatment ${ }^{14}$ which allow construction of full arch fixed porcelain fused to metal implant supported prostheses.

For complete-arch fixed implant supported prostheses several types of prosthetic materials are used. Titanium is used for computer-aided design and computer-aided manufacturing (CAD-CAM) because of its excellent mechanical properties ${ }^{15}$. The metal-ceramic restoration comprised cobalt chromium framework covered with porcelain veneers. Such framework is rigid, has a higher modulus of elasticity, had excellent mechanical properties, and may be cut and reassembled in case of misfits ${ }^{16}$. However, they associated with several prosthetic complications, for example, fracture of porcelain veneers, screws loosening ${ }^{17}$, and warpage of the metal substructure during porcelain firing, which make problems in passive $\mathrm{fit}^{18}$. Moreover, these materials are very stiff and lack shock absorption which may transfer high forces to the implant via the superstructure ${ }^{19}$. Also, titanium and cobalt chromium frameworks may cause esthetic problems, corrosion, allergy and degradation ${ }^{20,21}$. Several materials may be used for veneers such as porcelains, acrylic resins, and composite resins. To decrease impact forces, weight of the prosthesis, and cost, composite veneers may be used especially complete full arch fixed prosthesis, instead of porcelain. Composite has good esthetics and stable in color than acrylic resin ${ }^{15}$.

Polyetheretherketone (PEEK) is a high-performance thermoplastic polymer which can be utilized as a metal substitute for fixed and removable restoration. This material has several advantages such as strength to weight ratio, corrosion resistance, biocompatibility, compatibility with medical imaging, low plaque affinity and chemical stability ${ }^{22-24}$. Moreover, it has good mechanical behavior, creep, wear resistance and shock absorbing ability ${ }^{19,25}$. These criteria make the PEEK material a useful substitute to metal frameworks for fixed implant supported restorations. PEEK has radiolucency, which enable ease detection of screw loosening. PEEK has also low weight that allow construction of light restoration which increase comfort and satisfaction during function ${ }^{18}$. The PEEK material can be fabricated by either computer aided design/computer aided manufacturing (CAD/CAM) or by injection molding ${ }^{18}$. PEEK material was modified by adding $20 \%$ ceramic fillers (High performance polymer, BioHPP; bredent GmbH \& Co KG) to increase the modulus of elasticity. BioHPP is elastic as bone, act as shock absorber and decrease the occlusal stresses transmitted to the prosthesis and opposing denti$\operatorname{tion}^{26}$. Moreover, it has high bond strength to acrylic resin (polymethyl methacrylate) and to indirect composite resin ${ }^{27,28}$ through primer provided by the manufacture (visio.link; bredent). When BioHPP used for implant frameworks, it can be veneered 
with acrylic resin denture teeth or light-polymerized indirect composite resin ${ }^{18}$.

Reviewing the literature, studies evaluating and comparing metal and PEEK full arch fixed restorations in subjects with mandibular ridge atrophy are scarce. Therefore, the aim of the present randomized clinical trial was to evaluate clinical and radiographic outcomes of poly ether-ether ketone veneered with composite and porcelain/metal complete arch fixed screw retained restoration for atrophied mandibular ridges after one year.

\section{MATERIALS AND METHODS}

\section{Patient cohort}

This study was conducted at Removable Prosthodontic Department, Faculty of Dentistry, Assiut University. On a convenient sample of 8 (4 men and 4 women) edentulous patients (mean age of 58 years) with the following inclusion criteria: 1) All patients complained from mandibular ridge atrophy with inadequate stabilization of their mandibular dentures, 2) Patients presented need for a fixed implant-restoration, 3) Good bone amount (class IV-VI Cawood and Howell ${ }^{29}$ and density in the interforaminal area and posterior mandibular regions of the mandible (at least $10 \mathrm{~mm}$ bone height available) as verified by perioperative cone beam computerized tomography. Exclusion criteria include: 1) General contraindications for surgical procedures such as patients with head and neck radio therapy, patients with bleeding disorders, hepatic patients, 2) Patients with diseases that jeopardize implant healing such as diabetes mellitus, and osteoporosis, 3) Long term immunosuppressive and corticosteroid drug therapy and smoking patient. All patients signed informed consents and the study plan was approved by local ethical committee. The patients were categorized by age, gender, and bone height in the posterior mandibular regions of the mandible and were randomly assigned into 2 groups using balanced randomization, then comparison of baseline criteria between groups was made to ensure that was no difference in age, gender, and bone height between groups to avoid selection bias. Randomization was performed using random generated numbers in excel program. Group I included 4 patients ( 2 males and 2 females) who received 8 implants and porcelain fused to metal full arch fixed restoration (control group), Group II included 4 patients ( 2 males and 2 females) who received 8 implants and Poly ether-ether (PEEK) fixed restoration veneered with composite (test group).

\section{Surgical procedures}

Radiopaque gutta perchae markers are added to the denture at labial, buccal and lingual flanges. Dual scan protocol was followed using cone beam CT (CBCT, i-CAT, Imaging Sciences International ISI, Pennsylvania, USA), Firstly, the patients were scanned while wearing their mandibular dentures, then the mandibular dentures were scanned alone. The two data sets of the double scans were overlapped then opened with 3-D image treatment designing software (OnDemand). According to the CT scan, the implants were virtually planned as follows; 4 conventional implants in the interforaminal area and 4 short implants posterior to the mental foramina ( 2 implants on each side), then an individualized stereolithographic surgical guide was constructed using prototyping technique. Virtual model planning software was used to define the sites for implant placement and anchor pins for the surgical guide. A tissue born stereolithographic guide (fig 2) with 8 metal rings placed above the implant positions was fabricated using 3D printing process (In2Guide).

The universal surgical kit (In2Guide, Universal Kit Cybermed Inc) was used in osteotomy preparation (fig 1). This kit includes hand drill sleeves that fit the template sleeves with successive diameters. The template was fixed to mandibular bone by anchor pins. Eight implants (Dentium Co., Seoul, Korea) were inserted using one stage surgical approach at 35 $\mathrm{Ncm}$ torque. Healing abutments of adequate gingival 
height were connected to the implants and the old dentures were relieved and relined with resilient liners. The occlusion was refined. Postoperative medications include; Antibiotics (amoxicillin 625 mg + clavulanic acid 125 mg, Augmentin $\left.{ }^{\circledR} 1 \mathrm{gm}\right)$, Corticosteroids (Dexamethazone ${ }^{\circledR}$ ) injection immediately after surgery to reduce postoperative edema and inflammation. Anti-inflammatory medication (ibuprofen ${ }^{\circledR}, 600 \mathrm{mg}$ ) was administered for 5 days postoperatively.

Analgesics (Ketolac ${ }^{\circledR} 10 \mathrm{mg}$ ) were given on the day of surgery and postoperatively for the first 5 days. Participants were informed to eat soft diet and avoid hard foods. Post-operative panoramic radiographs were made to ensure proper implant placement (fig 2)

After 3 months of osseointegration, healing abutments were unthreaded and multiunit abutments were connected to the implants. Open tray impression was made. Custom acrylic tray was constructed. The abutment level impression posts were threaded to the multi-unit abutment and splinted with Duralay (Duralay, Reliance Dental MFG Co, Worth, IL, USA) acrylic resin to avoid movements. Light body rubber base impression (SPEEDEX, Coltene/Whaledent Pvt., Ltd., 9450 Alstalten, Switzerland) was injected around the transfer coping, and the impression was complete

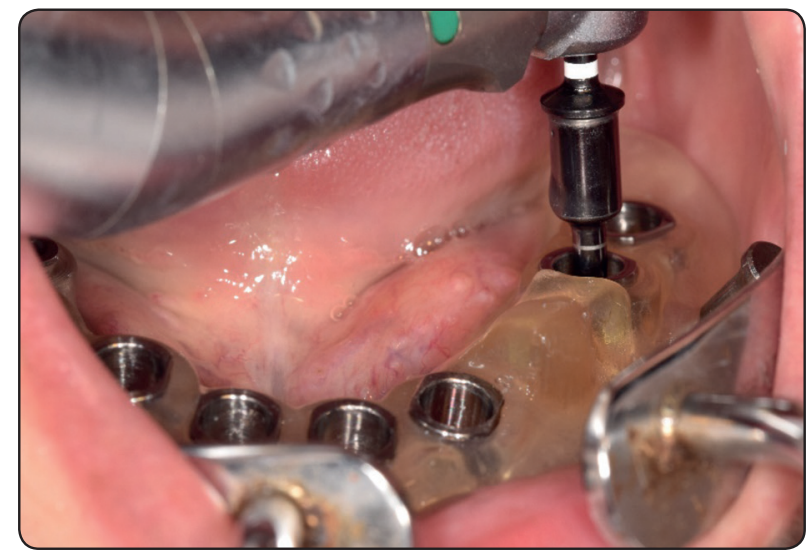

Fig. (1) Osteotomy preparation using the sterolithographic guide. with putty material. The posts were unscrewed and the impression was removed from patient mouth. Abutment analogues were threaded to the transfer coping and the impression was poured to obtain master cast. Record blocks were fabricated on the casts and used to record jaw relationship. Appropriate lip support was restored. Plastic caps (group I) and titanium caps (group II) of multiunit abutments were connected to the analogue of abutments on the master cast. The model was scanned using a computer aided device/ computer aided manufacturing (Ceramill, Amann Girrbach, Austria), then a fixed prosthesis was designed using the software of the device with 14 teeth in both groups and printed by prototyping using a castable resin (Duralay, Reliance Dental MFG Co, Worth, IL, USA), then tried in patient mouth. For group I, the resin pattern was cast with Cobalt chromium alloy (Heraeus-Kulzer, Germany), tried in patient mouth for passive fit. The porcelain powder (VITA Zahnfabrik, Bad Säckingen, Germany) was added to the metal substructure, fired, then glazed in usual manner. Lost gingival tissues were replaced by pink porcelain if needed (fig 3). For group II, the resin pattern was invested and converted to PEEK framework by injection mold technique. BioHPP pellets material (Bredent GmbH \& Co.KG, Weißenhorner Str. 2, 89250 Senden, Germany) was pressed into the mold. Visio.link Adhesive was

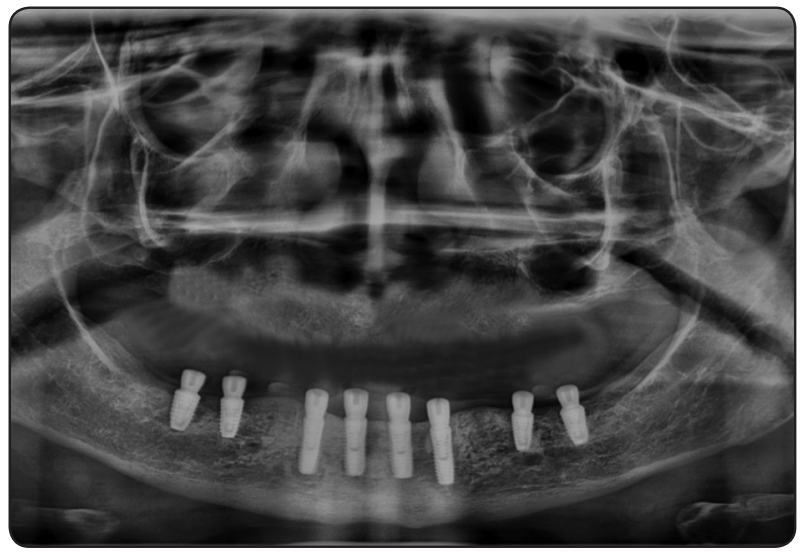

Fig. (2) Post-Operative panoramic radiographs 
painted above the frame work to facilitate bonding of Visio.lign composite veneers that replaces teeth and pink composite for gingival tissues were boned to the BioHPP using the Adhesive (fig 4). Participants were instructed to perform adequate cleaning and to attend regularly to perform necessary adjustments and to collect data.

\section{Evaluation of clinical and radiographic outcomes}

Clinical and radiographical evaluations were performed at time of prosthesis insertion, 6 months and 12 months later.

\section{Clinical outcome}

Plaque (PI) and bleeding (BI) parameters were measured using indices of Mombelli et al. ${ }^{30}$. Graduated periodontal probe was used to measure the distance from gingival margin to the depth of the probing and considered probing depth (PD). The PI, BI and PD were evaluated in lingual, mesial, buccal, and distal side of each implant. Implant stability quotient (ISQ) was measured using Osstell device (Integration Diagnostics). A smart peg was connected to the implant, and 2 readings (mesially and distally), were performed for each implant ${ }^{31}$. All measurements were made by blind periodontist.

\section{Radiographic outcome}

Radiographic assessments of marginal bone loss were made using a cone beam $\mathrm{CT}$ according to the method described previously ${ }^{32} . \mathrm{N}$ the axial image view of the computerized tomography (CT) of the mandible, the software tools were used to bisect each implant mesiodistal and labiolingual directions.

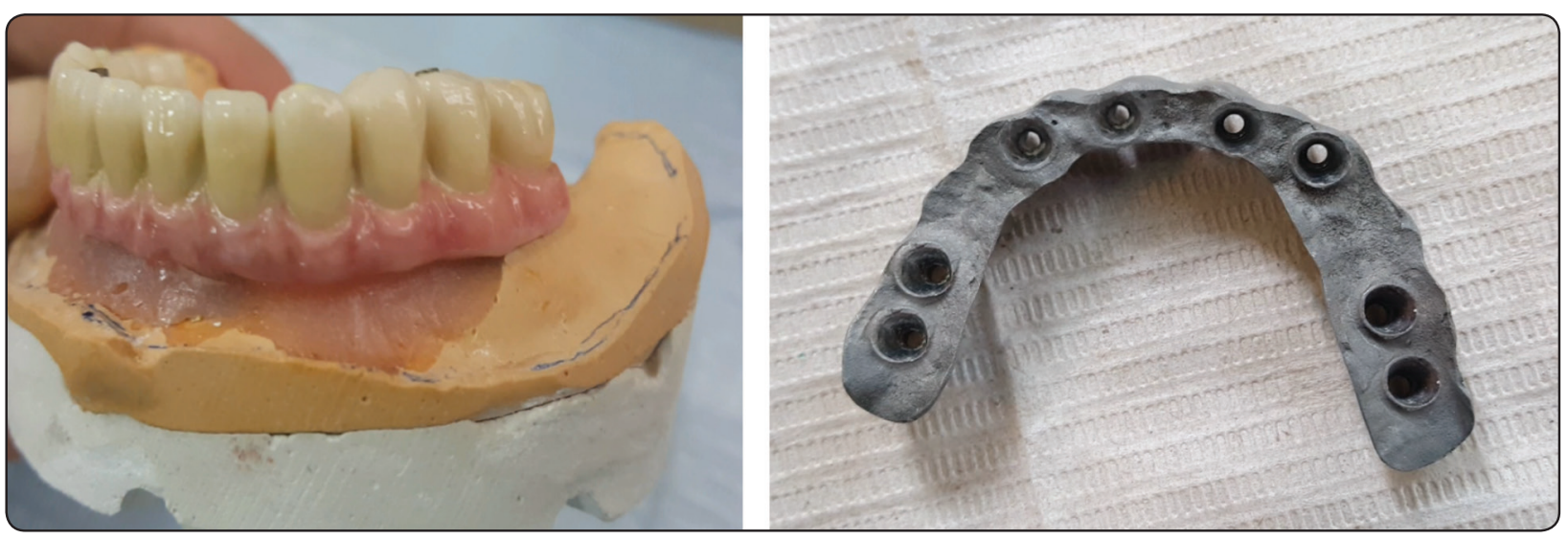

Fig. (3) Group I: Fixed porcelain fused to metal prosthesis

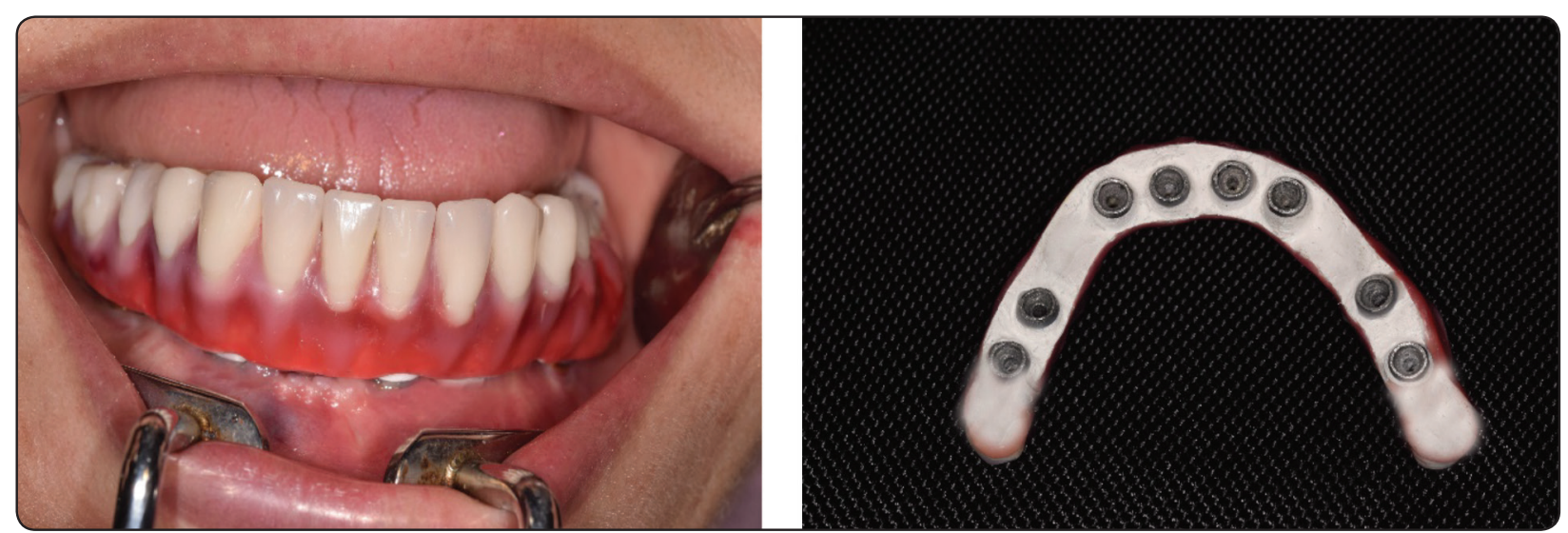

Fig. (4) Group II: Fixed PEEK prosthesis veneered with composite resin 
For image analysis, software (OnDemand3D CD Viewer) was used to measure vertical bone loss. The distance between implant platform and first bone to implant contact indicated vertical bone level. Bone resorption was calculated by subtracting bone level values after 6 and 12 months from measures at base line. Marginal bone loss was calculated lingually, mesially, buccally, and distally and the mean was recorded on patient level.All calculations were made by independent blind radiologist. All calculations were made by independent blind radiologist.

\section{Statistical methods}

One-Sample Kolmogorov-Smirnov Test was used to test normal distribution of data. Comparisons between groups for all clinical and radiographic parameters were made by Mann-Whitney test. The Friedman test and Wilcoxon's test were used to detect significant differences in tested parameters between observation times. Kaplan-Meyer analysis was performed for implant survival rates and Log rank test was used to compare survival between groups. P-values $<0.05$ were considered to be significant. All statistical analyses were performed using statistical software (SPSS 25)

\section{RESULTS}

A total of 64 implants were placed in both groups. Three posterior (short) implants failed in two patient belongs to $\mathrm{G} 2$ after 6 months resulted in $90.7 \%$ survival rate and no failure detected in G2 (implant survival was 100\%). Kaplan-Meier analysis of survival rate between groups is showed in fig 5. PEEK group showed significant higher implant survival rate than metal group (Log rank test, $\mathrm{p}=.048$ ) after one year. The failed implants were removed and the prosthesis was screwed to the remaining implants. All patients attend the follow up visits without dropouts.

The results of clinical parameters (PI scores, GI scores, PD scores and ISQ) and radiographic (marginal bone loss) at various observation times are shown in table 1. Multiple comparisons of clinical and radiographic parameters between time intervals are demonstrated in table 2. Plaque index (PI) increased with time in metal group only (Freidman test, $\mathrm{p}=.005$ ) and PEEK group showed no difference in plaque scores between observations. Multiple comparisons between observation times showed significant difference in PI between each 2-time intervals (Wilcoxon sign ranked test, $\mathrm{p}<.05$ ) in metal group (table 2). Metal group showed higher plaque scores than PEEK group after 6months and one year. ( $\mathrm{p}=.025$ and .007 respectively). Gingival index (GI) increased with time in metal group only (Freidman test, $\mathrm{p}=.024$ ) and PEEK group showed no difference in plaque scores between observations. Multiple comparisons between observation times showed significant difference in GI between each 2-time intervals (Wilcoxon sign ranked test, $\mathrm{p}<.05$ ) in metal group (table 2). Metal group showed higher gingival scores than PEEK group after 6months and one year ( $\mathrm{p}=.049$ and .011 respectively).

Probing depth (PD) increased with time in metal and PEEK (Freidman test, $\mathrm{p}=.002$ and .045 respectively, table 1). Multiple comparisons between observation times showed significant difference in PD between each 2 observation times (Wilcoxon sign ranked test, $\mathrm{p}<.05$ ) in metal group only (table $2)$. For PEEK group no significant difference in PD between 6 months and 12 months. Metal group recorded significant higher PD than PEEK group after 6months and one year $(\mathrm{p}=.039$ and .013

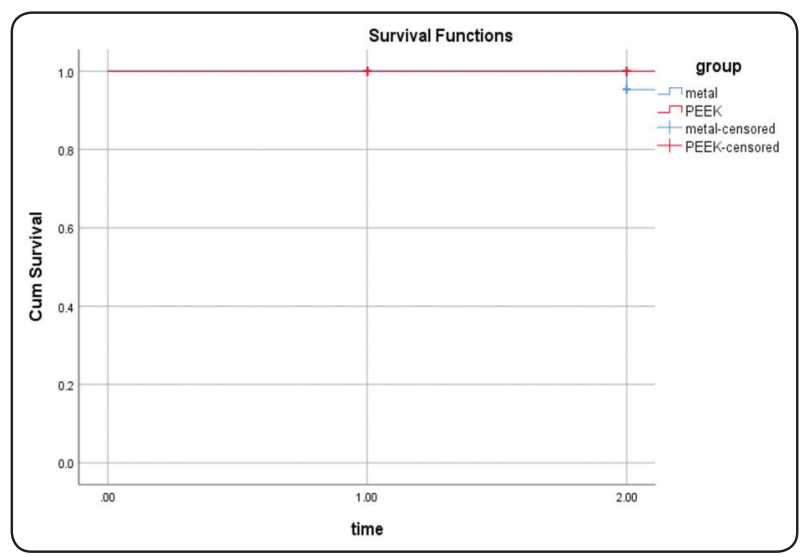

Fig. (5) Kaplan-Meier analysis of survival rate between groups 
respectively). No difference in stability of implants was noted between observation times or between groups. Marginal bone loss increased from 6 months to 12 months in both groups (Freidman test, $\mathrm{p}=.003$ and .008 for metal and PEEK groups respectively) (table 1). Metal group showed significant higher bone loss than PEEK group after 6months and one year ( $\mathrm{p}=.009$ and .021 respectively).

TABLE (1) Comparison of measured parameters between metal and PEEK

\begin{tabular}{|c|c|c|c|c|}
\hline & Base line & 6 months & 12 months & Freidman test \\
\hline \multicolumn{5}{|c|}{ Plaque index $(\mathrm{PI})$} \\
\hline Metal (MD (mini-maxi)) & $0.0(.00-1.0)$ & $2(1.0-2.0)$ & $3.0(1.0-3.0)$ & $.005^{*}$ \\
\hline PEEK (MD (mini-maxi)) & $0.0(.00-1.0)$ & $.5(.00-1.0)$ & $1.0(.00-2.0)$ & .12 \\
\hline Mann-Whitney test & 1.00 & $.025^{*}$ & $.007 *$ & \\
\hline \multicolumn{5}{|c|}{ Gingival index (GI) } \\
\hline Metal (MD (mini-maxi)) & $.0(.00-1.0)$ & $1.0(.00-1.0)$ & $2(1.00-3.0)$ & $.024 *$ \\
\hline PEEK (MD (mini-maxi)) & $.0(.00-0.0)$ & $0.0(.00-1.0)$ & $0.0(.00-1.0)$ & .17 \\
\hline Mann-Whitney test & .86 & $.049 *$ & $.011 *$ & \\
\hline \multicolumn{5}{|c|}{ Probing depth (PD) } \\
\hline Metal $(\mathrm{X} \pm \mathrm{SD})$ & $1.1 \pm .91$ & $2.1 \pm .42$ & $2.9 \pm 3.1$ & $.002 *$ \\
\hline PEEK $(\mathrm{X} \pm \mathrm{SD})$ & $1.2 \pm .65$ & $1.6 \pm .35$ & $1.7 \pm .23$ & $.045^{*}$ \\
\hline Mann-Whitney test & .56 & $.039 *$ & $.013 *$ & \\
\hline \multicolumn{5}{|c|}{ Implant stability Quotients (ISQ) } \\
\hline $\operatorname{Metal}(\mathrm{X} \pm \mathrm{SD})$ & $66.3 \pm 3.6$ & $66.8 \pm 2.7$ & $67.4 \pm 3.9$ & .095 \\
\hline PEEK $(\mathrm{X} \pm \mathrm{SD})$ & $67.8 \pm 4.1$ & $67.5 \pm 4.4$ & $68.2 \pm 3.2$ & .10 \\
\hline Mann-Whitney test & .59 & .69 & .33 & \\
\hline \multicolumn{5}{|c|}{ Marginal bone loss (MBL) } \\
\hline Metal $(\mathrm{X} \pm \mathrm{SD})$ & - & $1.1 \pm .25$ & $1.4 \pm .35$ & $.003 *$ \\
\hline PEEK $(\mathrm{X} \pm \mathrm{SD})$ & - & $.76 \pm .37$ & $.94 \pm .32$ & $.008 *$ \\
\hline Mann-Whitney test & - & $.009 *$ & $.021 *$ & \\
\hline
\end{tabular}

MD: median, mini: minimum, maxi: maximum, $X$ : mean, SD: standard deviation. *: p is significant at 5\%

TABLE (2) Post-hoc multiple comparisons between each 2-time intervals for metal and PEEK groups

\begin{tabular}{|c|c|c|c|}
\hline & Base line- 6 months & Base line- 12 months & 6 months-12months \\
\hline \multicolumn{4}{|c|}{ Plaque Scores (PI) } \\
\hline Metal & $.048 *$ & $.006^{*}$ & $.015 *$ \\
\hline PEEK & .48 & .28 & .39 \\
\hline \multicolumn{4}{|c|}{ Gingival Scores (GI) } \\
\hline Metal & $.036^{*}$ & $.025 *$ & $.006 *$ \\
\hline PEEK & .56 & .29 & .35 \\
\hline \multicolumn{4}{|c|}{ Probing depth (PD) } \\
\hline Metal & $.015 *$ & $.017 *$ & $.021 *$ \\
\hline PEEK & $.015 *$ & $.035 *$ & .48 \\
\hline \multicolumn{4}{|c|}{ Implant stability Quotients (ISQ) } \\
\hline Metal & .38 & .46 & .29 \\
\hline PEEK & .18 & .91 & .45 \\
\hline \multicolumn{4}{|c|}{ Marginal bone loss (MBL) } \\
\hline Metal & - & - & $.008 *$ \\
\hline PEEK & - & - & $.037 *$ \\
\hline
\end{tabular}




\section{DISCUSSION}

The flapless surgical approach was used in this study as it has several advantages including; minimal post-operative discomfort, reduced edema (no sutures or open wound) ${ }^{33,34}$. Moreover, the flapless approach reduced the peri-implant bone loss as reflection of the flap cause mucoperiosteal stripping that may induce bone loss around the implants ${ }^{35}$. Stereolithographic surgical stent allows accurate 3-dimentional placement of the implants in planned implant position. The conventional stent and the 2-dimensional panoramic radiographs are not capable for accurate visualization of bone and vital structure position in buccolingual dimension. ${ }^{36}$

Cone beam computerized tomography (CBCT) was used for evaluation of marginal bone resorption as it provides information on bone loss on buccal and lingual aspects of the implants as well as mesial and distal aspects due to its three-dimensional nature. In contrast, Periapical radiography are 2 dimensional only. Moreover, CBCT, can be used easily especially elevated floor of the mouth without causing patient discomfort as periapical radiographs do. CBCT also has no magnification or distortion as panoramic radiographs ${ }^{37,38}$. The use of CBCT in measuring bone resorption around implants was recommended by other investigators ${ }^{39,40}$.

Metal ceramic group was asscoiated with higher implant failures than PEEK veneered with composite. The increased survival of the implants with PEEK agreed with the results of Malo et al. ${ }^{41}$ Who reported $100 \%$ implant survival rate for PEEK fixed All on four maxillary prosthesis after one year. On the other hand, the reduced survival rate in the metal group may be attributed to the heavy weight of the prosthesis which transmit more forces to the implants.

The plaque scores increased significantly with time for anterior and posterior implants. The increased plaque stagnation may be due to decreased manual ability of old participants causing impaired cleaning. Another explanation may be attributed to the inability to remove the prosthesis by the patients and performing adequate oral hygiene and cleaning similar to removable prosthesis. The reduced plaque accumulation of PEEK compared to metal could be due to the reduced affinity of PEEK to plaque accumulation and ${ }^{22,24}$. In line with this finding, Klur, et al. ${ }^{42}$ found that PEKK-made restorations offer a good and stable alternative to CoCr-made restorations particularly in improving the oral hygiene. In line with this observation, Wachtel et al. ${ }^{43}$ evaluated bacterial tightness of screw-retained PEEK crowns on titanium implants during masticatory simulation. They found that PEEK material has a sealing effect against bacterial leakage at the implant-abutment interface with no bacterial leakage which is advantageous compared to superstructures of conventional materials. The decreased gingival inflammation with PEEK group compared to metal group may be attributed to the decreased plaque accumulation which is also responsible for lack of difference in GI between time intervals. The causal relation between plaque and gingival inflammation was previously reported ${ }^{41}$

Probing depth increased significantly with passage of time. This may be related to the high bone resorption and gingiva enlargement ${ }^{44}$. PEEK group recorded reduced probing depth than metal group. This may be due to the decrease in plaque accumulation and gingival inflammation of PEEK group. The relation between increased plaque scores, gingival scores and increased pocket depth was previously reported by Pontoriero et al.$^{45}$ who found that increase in mucositis severity, including inflammation of the soft tissues was associated with peri-implant pockets.

Ostell device was used to evaluate implant mobility as it is noninvasive and allow verification after unscrewing of the prosthesis ${ }^{46}$. Implant mobility values obtained in in this study were above 60. The lack of difference in implant mobility between metal and PEEK prostheses was not surprising and concurred with the results of other authors $^{32,47}$ and may be due to the increased bone 
quality in the mandible and increased bone to implant contact and implant anchorage in the bone as functional implant loading was performed after complete ossointegration (after 3 months) in both groups.

The mean bone loss after one year for metal $(1.4 \pm .35)$ and PEEK (.94 \pm .32$)$ groups was within the accepted standards reported in the literature ${ }^{48}$. Bone loss increased from 6 months to 12 months in both groups. This was expected as bone loss usually increased with time due to exposure to bone remodeling combined with increased functional stresses. The reduced bone loss in PEEK group compared to metal group could be attributed to several reasons. The PEEK frame covered with composite resin teeth has a modulus of elasticity lower than cobalt chromium framework covered with porcelain and close to the modulus of elasticity of the bone. Therefore, it has a dampening effect and absorb and reduce the occlusal forces to the implants from the opposing dentition ${ }^{26}$. It has been showed that PEEK's low elasticity modulus together with veneered composite resin teeth is advantageous over metal-supported ceramics in reducing the occlusal forces ${ }^{49}$. Moreover, BioHPP frameworks was found to have good marginal fit (similar to titanium) and fracture resistance which make it a good alternative to metal substractures ${ }^{15}$. The marginal fit prevent prosthetic complications as screw loosening and biologic complications as bacterial stagnation which may affect peri-implant tissues ${ }^{50}$. On the other hand, stiff frameworks such as cobalt chromium are associated with heavy occlusal loading and may transmit increased stress to the implants ${ }^{18}$. In line with this explanation, Tekin et al. ${ }^{49}$ compare peri-implant stresses with PEEK as an alternative to titanium and metal prosthesis and found that PEEK material reduces the stresses on the implant and abutments caused by the force applied. They added that PEEK decreased the stress by spreading the incoming forces to the implant, crowns, and screws as compared with the titanium abutments. Also, PEEK is lighter than cobalt chromium, thus reducing stresses than metal ceramic restoration and alleviates the forces generated during chewing due to its elasticity, thus reduce the rate of bone resorption

The small patient cohort, and the short evaluation period are evident limitations of this investigation. Therefore, long term clinical trials with sufficient sample size are needed to confirm the findings of this study. Moreover, studying the peri-implant hard and soft tissue only is a part of the entire clinical picture. Therefore, future studies are needed to evaluate patient based and prosthetic outcomes of the tested prosthesis on the long-term perspective.

\section{CONCLUSION}

Within the limitations short term randomized trial, it could be concluded that Poly ether-ether ketone veneered with composite full arch fixed screw retained prosthesis is advantageous than Porcelain/ metal restoration for patients with atrophied mandibular ridges as it recorded favourable periimplant tissue health after one year.

\section{REFERENCES}

1. Vervoorn JM, Duinkerke AS, Luteijn F, Poel A. Assessment of denture satisfaction. Community Dentistry and Oral Epidemiology. 1988;16:364-7.

2. Van Waas MA. The influence of clinical variables on patients' satisfaction with complete dentures. The Journal of prosthetic dentistry. 1990;63:307-10.

3. Wolff A, Gadre A, Begleiter A, Moskona D, Cardash H. Correlation between patient satisfaction with complete dentures and denture quality, oral condition, and flow rate of submandibular/sublingual salivary glands. International Journal of Prosthodontics. 2003;16.

4. Ikebe K, Matsuda K-i, Morii K, Furuya-Yoshinaka M, Nokubi T, Renner RP. Association of masticatory performance with age, posterior occlusal contacts, occlusal force, and salivary flow in older adults. International Journal of Prosthodontics. $2006 ; 19$.

5. Koshino H, Hirai T, Ishijima T, Ikeda Y. Tongue motor skills and masticatory performance in adult dentates, elderly dentates, and complete denture wearers. The journal of prosthetic dentistry. 1997; 77:147-52. 
6. Ikebe K, Amemiya M, Morii K, Matsuda K-i, Furuya-Yoshinaka M, Yoshinaka $\mathrm{M}$ et al. Association between oral stereognostic ability and masticatory performance in aged complete denture wearers. International Journal of Prosthodontics. $2007 ; 20$.

7. Weinstein R, Agliardi E, Fabbro MD, Romeo D, Francetti L. Immediate Rehabilitation of the Extremely Atrophic Mandible with Fixed Full-Prosthesis Supported by Four Implants. Clinical implant dentistry and related research. 2012;14:434-41.

8. Sadowsky SJ. The implant-supported prosthesis for the edentulous arch: design considerations. J Prosthet Dent. 1997;78:28-33.

9. Malo P, Rangert B, Nobre M. "All-on-Four” immediate-function concept with Branemark System implants for completely edentulous mandibles: a retrospective clinical study. Clin Implant Dent Relat Res. 2003;5 Suppl 1:2-9.

10. Malo P, Rangert B, Nobre M. All-on-4 immediate-function concept with Branemark System implants for completely edentulous maxillae: a 1-year retrospective clinical study. Clin Implant Dent Relat Res. 2005;7 Suppl 1:S88-94.

11. Rangert B, Krogh PH, Langer B, Van Roekel N. Bending overload and implant fracture: a retrospective clinical analysis. International journal of oral \& maxillofacial implants. 1995;10.

12. Duyck J, Oosterwyck H, Sloten J, Cooman M, Puers R, Naert I. Magnitude and distribution of occlusal forces on oral implants supporting fixed prostheses: an in vivo study. Clinical oral implants research. 2000;11:465-75.

13. Brånemark PI, Svensson B, Van Steenberghe D. Ten-year survival rates of fixed prostheses on four or six implants ad modum Brånemark in full edentulism. Clinical oral implants research. 1995;6:227-31.

14. Renouard F, Nisand D. Short Implants in the Severely Resorbed Maxilla: A 2-Year Retrospective Clinical Study. Clinical Implant Dentistry and Related Research. 2005;7.

15. Jin HY, Teng MH, Wang ZJ, Li X, Liang JY, Wang WX et al. Comparative evaluation of BioHPP and titanium as a framework veneered with composite resin for implant-supported fixed dental prostheses. J Prosthet Dent. 2019;122:383-8.

16. Silva TB, De Arruda Nobilo MA, Pessanha Henriques GE, Mesquita MF, Guimaraes MB. Influence of laser-welding and electroerosion on passive fit of implant-supported prosthesis. Stomatologija. 2008;10:96-100.

17. Sailer I, Philipp A, Zembic A, Pjetursson BE, Hammerle CH, Zwahlen M. A systematic review of the performance of ceramic and metal implant abutments supporting fixed implant reconstructions. Clin Oral Implants Res. 2009;20 Suppl 4:4-31.
18. Zoidis P. The all-on-4 modified polyetheretherketone treatment approach: A clinical report. J Prosthet Dent. 2018;119:516-21 .

19. Conserva E, Menini M, Tealdo T, Bevilacqua M, Ravera G, Pera $\mathrm{F}$ et al. The use of a masticatory robot to analyze the shock absorption capacity of different restorative materials for prosthetic implants: a preliminary report. Int J Prosthodont. 2009;22:53-5.

20. Bidra AS, Rungruanganunt P. Clinical outcomes of implant abutments in the anterior region: a systematic review. J Esthet Restor Dent. 2013;25:159-76.

21. Takaba M, Tanaka S, Ishiura Y, Baba K. Implant-supported fixed dental prostheses with $\mathrm{CAD} / \mathrm{CAM}$-fabricated porcelain crown and zirconia-based framework. J Prosthodont. 2013;22:402-7.

22. Hahnel S, Wieser A, Lang R, Rosentritt M. Biofilm formation on the surface of modern implant abutment materials. Clin Oral Implants Res. 2015;26:1297-301.

23. Wang H, Xu M, Zhang W, Kwok DT, Jiang J, Wu Z et al. Mechanical and biological characteristics of diamond-like carbon coated poly aryl-ether-ether-ketone. Biomaterials. 2010;31:8181-7.

24. Zoidis P, Papathanasiou I, Polyzois G. The Use of a Modified Poly-Ether-Ether-Ketone (PEEK) as an Alternative Framework Material for Removable Dental Prostheses. A Clinical Report. J Prosthodont. 2016;25:580-4.

25. Rosentritt M, Schneider-Feyrer S, Behr M, Preis V. In Vitro Shock Absorption Tests on Implant-Supported Crowns: Influence of Crown Materials and Luting Agents. Int J Oral Maxillofac Implants. 2018;33:116-22.

26. Suwannaroop P, Chaijareenont P, Koottathape N, Takahashi $\mathrm{H}$, Arksornnukit M. In vitro wear resistance, hardness and elastic modulus of artificial denture teeth. Dent Mater J. 2011; 30:461-8

27. Fuhrmann G, Steiner M, Freitag-Wolf S, Kern M. Resin bonding to three types of polyaryletherketones (PAEKs)durability and influence of surface conditioning. Dent Mater. 2014;30:357-63.

28. Keul C, Liebermann A, Schmidlin PR, Roos M, Sener B, Stawarczyk B. Influence of PEEK surface modification on surface properties and bond strength to veneering resin composites. J Adhes Dent. 2014;16:383-92.

29. Cawood JI, Howell RA. A classification of the edentulous jaws. Int J Oral Maxillofac Surg. 1988;17:232-6.

30. Mombelli A, van Oosten MA, Schurch E, Jr., Land NP. The microbiota associated with successful or failing osseointegrated titanium implants. Oral Microbiol Immunol. 1987;2:145-51. 
31. Kronstrom M, Davis B, Loney R, Gerrow J, Hollender L. A prospective randomized study on the immediate loading of mandibular overdentures supported by one or two implants: a 12-month follow-up report. Int J Oral Maxillofac Implants. 2010;25:181-8.

32. Elsyad MA, Al-Mahdy YF, Fouad MM. Marginal bone loss adjacent to conventional and immediate loaded two implants supporting a ball-retained mandibular overdenture: a 3-year randomized clinical trial. Clin Oral Implants Res. 2012;23:496-503.

33. Campelo LD, Camara JR. Flapless implant surgery: a 10-year clinical retrospective analysis. Int J Oral Maxillofac Implants. 2002;17:271-6.

34. Elsyad MA. A new surgical template with a handpiece positioner for use during flapless placement of four dental implants to retain a mandibular overdenture. J Prosthodont. 2012;21:573-7.

35. Caneva M, Botticelli D, Salata LA, Souza SL, Bressan E, Lang NP. Flap vs. "flapless" surgical approach at immediate implants: a histomorphometric study in dogs. Clin Oral Implants Res. 2010;21:1314-9.

36. Lal K, White GS, Morea DN, Wright RF. Use of stereolithographic templates for surgical and prosthodontic implant planning and placement. Part II. A clinical report. J Prosthodont. 2006;15:117-22.

37. Naitoh M, Hayashi H, Tsukamoto N, Ariji E. Labial bone assessment surrounding dental implant using cone-beam computed tomography: an in vitro study. Clin Oral Implants Res. 2012;23:970-4.

38. Raes F, Renckens L, Aps J, Cosyn J, De Bruyn H. Reliability of circumferential bone level assessment around single implants in healed ridges and extraction sockets using cone beam CT. Clin Implant Dent Relat Res. 2013;15:661-72.

39. Razavi T, Palmer RM, Davies J, Wilson R, Palmer PJ. Accuracy of measuring the cortical bone thickness adjacent to dental implants using cone beam computed tomography. Clin Oral Implants Res. 2010;21:718-25.

40. Elsyad MA, Khirallah AS. Circumferential bone loss around splinted and nonsplinted immediately loaded implants retaining mandibular overdentures: A randomized controlled clinical trial using cone beam computed tomography. J Prosthet Dent. 2016;116 741-8
41. Malo P, de Araujo Nobre M, Moura Guedes C, Almeida R, Silva A, Sereno N et al. Short-term report of an ongoing prospective cohort study evaluating the outcome of full-arch implant-supported fixed hybrid polyetheretherketone-acrylic resin prostheses and the All-on-Four concept. Clin Implant Dent Relat Res. 2018;20:692-702.

42. Klur T, Hasan I, Ottersbach K, Stark H, Fichte M, Dirk C et al. PEKK-made indirect temporary crowns and bridges: a clinical pilot study. Clin Oral Investig. 2019;23:771-7.

43. Wachtel A, Zimmermann T, Sutel M, Adali U, Abou-Emara M, Muller WD et al. Bacterial leakage and bending moments of screw-retained, composite-veneered PEEK implant crowns. J Mech Behav Biomed Mater. 2019;91:32-7.

44. ELsyad MA, Alameldeen HE, Elsaih EA. Four-implant-supported fixed prosthesis and milled bar overdentures for rehabilitation of the edentulous mandible: A 1-year randomized controlled clinical and radiographic study. Int J Oral Maxillofac Implants. 2019;34:1493-503.

45. Pontoriero R, Tonelli MP, Carnevale G, Mombelli A, Nyman SR, Lang NP. Experimentally induced peri-implant mucositis. A clinical study in humans. Clin Oral Implants Res. 1994;5:254-9.

46. Ayub KV, Ayub EA, Lins do Valle A, Bonfante G, Pegoraro T, Fernando L. Seven-Year Follow-up of Full-Arch Prostheses Supported by Four Implants: A Prospective Study. The International journal of oral \& maxillofacial implants. 2017;32:1351-8.

47. Elsyad MA, Elsaih EA, Khairallah AS. Marginal bone resorption around immediate and delayed loaded implants supporting a locator-retained mandibular overdenture. A 1-year randomised controlled trial. J Oral Rehabil. 2014;41:608-18.

48. Albrektsson T, Zarb G, Worthington P, Eriksson AR. The longterm efficacy of currently used dental implants: a review and proposed criteria of success. Int J Oral Maxillofac Implants. 1986;1:11-25

49. Tekin S, Deger Y, Demirci F. Evaluation of the use of PEEK material in implant-supported fixed restorations by finite element analysis. Niger J Clin Pract. 2019;22:1252-8.

50. Yilmaz B, Kale E, Johnston WM. Marginal discrepancy of CAD-CAM complete-arch fixed implant-supported frameworks. J Prosthet Dent. 2018;120:65-70. 